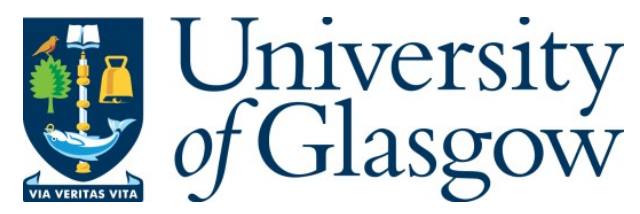

Chia, R. (2019) Becoming a learning organisation: A process-philosophical perspective. In: Ortenblad, A. (ed.) The Oxford Handbook of the Learning Organization. Series: Oxford handbooks. Oxford University Press: Oxford, United Kingdom. ISBN 9780198832355

(doi: 10.1093/oxfordhb/9780198832355.013.29)

This is the Author Accepted Manuscript.

There may be differences between this version and the published version. You are advised to consult the publisher's version if you wish to cite from it.

https://eprints.gla.ac.uk/173743/

Deposited on: 11 March 2019

Enlighten - Research publications by members of the University of Glasgow http://eprints.gla.ac.uk 


\section{Becoming a learning organization: a process-philosophical perspective}

Robert Chia

\section{Introduction}

The concept of learning organization has attracted much attention and scrutiny ever since its conception and articulation in the late 1980s. Robert Garratt (1986/2000) used the term the “learning organization” to refer to organizations in which top managers were able to learn continuously and to provide direction for setting up appropriate responses to environmental demands. In Garratt’s “Learning organization model,” directors would be the "business brains” that played the central role of integrators of information flows so much so that "learning and development through the adaptation of change to the whole" (Garratt 1986/2000, 78) could take place. Clearly Garratt construed the learning organization as top down driven and one largely based on a cognitivist understanding of learning and action. Three years later Pedler, Boydell, and Burgoyne (1989) published a paper in the journal Management Learning entitled "Towards the Learning Company" in which they articulated the key characteristics of what a learning organization comprised. These included: a learning approach to strategy; widespread participation in policy-making; informating; internal exchange; boundary scanning; learning climate; and self-development opportunities. For them, a learning organization was one which "facilitated the learning of all its members and consciously transforms itself and its context” (Pedler et al. 1989, 2, our emphasis). Pedler et al.'s contribution helped focus attention on the notion of a continuous learning environment, 
self-development of all organizational members and the institution of a reward system that fostered and valued personal contributions to the collective cause.

But it was not until Peter Senge (1990) published The Fifth Discipline: The Art and Practice of the Learning Organization, that the concept really took off and became a focus of theoretical and practical interest. His inspiring vision of what a learning organization comprised and the optimistic tone in which it was written, generated much enthusiasm particularly within the practitioner world even though there were those like Coopey (1995), who were more guarded about what they saw as his idealistic and utopian views. For Senge, “organizations learn only through individuals who learn.” Whilst “individual learning does not guarantee organizational learning, ... . without it no organizational learning occurs” (Senge 1990, 139). By focusing on the primacy of individual learning Senge commits himself to a methodological individualism which views the organization as merely an aggregation of individuals without an independent ontological status of its own. This assumption however is a questionable one as Cook and Yanow (1993) note. Notwithstanding this, following his emphasis, Senge (1990) identified five individual “disciplines” comprising “shared vision,” “systems thinking," “mental models,” "team learning,” and "personal mastery” that underpin what he calls the learning organization. Importantly for Senge and his collaborators (Kleiner, Smith, Roberts, Senge, and Ross 1994, 6), “practising a discipline is different from emulating a 'model'; there is always a danger of blindly applying ready-made recipes and 'best practices"” taken from others. For Senge and his collaborators, therefore, these disciplines are “individual lifelong programs of study and practice.” Practice and practising therefore is an individual matter rather than a "cultural” consideration (Cook and Yanow 1993) or, as we argue here, a mode of engagement that social theorists like Bourdieu (1990) call habitus; a collective modus operandi that predisposes us to engage in a manner consistent with the practices of a community. 
Since Senge's seminal articulation of what a learning organization comprises, there have been numerous attempts to elaborate on the notion (Santa 2015; Pedler and Burgoyne 2017; Örtenblad 2018) and to give it additional theoretical impetus. Whilst not always explicitly, in nearly all these theoretical efforts, however, the assumption remains that organizational learning is primarily an individual cognitive activity (Cook and Yanow 1993). But while Cook and Yanow offer a collective, cultural perspective, as a viable alternative to this individualistic focus, they still construe organizational learning as eminently reliant on “symbolic language” (Cook and Yanow 1993, 385) as the basis for achieving collectively shared "meanings." What defines cognitivism is an "information processing” model of the mind (Dreyfus 2002). It presumes that "perception, understanding, learning and action are all to be understood on the model of fact gathering, hypothesis information, inference making and problem solving” (Dreyfus 1988, 99). Such a dominant view of learning derives from an understanding of intelligence as the acquiring and following of abstract rules and meanings and using them to solve problems whether collectively or on an individual basis. According to Dreyfus, there are two main features of this cognitivist approach to learning and action: a) Our ability to deal with things intelligently using logic, reason and analysis as the basis for achieving an understanding; and b) This capacity to think about things rationally depends upon a faculty “for internal ‘automatic’ symbol manipulation” (Dreyfus 1988, 100) in interpreting and understanding the situation faced. This widespread understanding of what learning and intelligence comprises derives from a Platonic tradition that has been refined by Hobbes, Descartes, and Leibniz. It provides the foundation for the Artificial Intelligence research program at MIT inspired by the work of Herbert Simon and Allen Newell who were themselves pioneers of the information processing approach to artificial intelligence.

Dreyfus, who was himself at MIT in the 1960s but a trenchant critic of the AI program there over the past 50 years, has consistently argued that the most "basic forms of intelligent 
behavior, learning, and skillful action, can be described and explained without recourse to mind or brain representations” (Dreyfus 2002, 367). There is no need to presume abstract symbolic manipulation and hence meaning and interpretation in understanding intelligent and/or skilful behaviour. For him, much learning happens non-deliberately, unconsciously and unintentionally through collectively-sanctioned and transmitted material practices rather than through consciously-shared cultural meanings and understanding. Indeed, such social practices provide the necessary substratum for conscious cognitive learning (whether individual or collective) to take place. This idea that learning need not depend on mental cognition and representation has also been explored and argued by ecological psychologists including especially the husband and wife team James Gibson and his wife Eleanor Gibson (Gibson 1979; Gibson and Gibson 1955). Both emphasized learning in perceptual rather than cognitivist terms and it is this notion of active perception as a pre-conceptual form of learning that provides the basis for the grounding of what I call a "becoming" approach to the learning organization. Both Dreyfus and the Gibsons have cogently articulated an alternative understanding of learning that is fundamentally non-cognitive and action-based. In some ways it is reminiscent of Revans’s (1980) seminal contribution to “action learning” which was subsequently elaborated and developed in the context of management and organizational learning by several proponents including Pedler (1991), Raelin (1997), Marquardt (2000), and Hale (2014). Yet, what differentiates a becoming approach to the learning organization from these earlier contributions is an emphasis on collective rather than individual learning; one that is achieved, not through acquiring abstract cultural symbols and shared meanings, but through the material aggregation of a multitude of practical coping actions taken in situ, into established organizational sensitivities, predispositions, and practices.

This emphasis on the collective learning of predispositions and practices is inspired by the recent “practice turn” in social theory (Bourdieu 1990; Schatzki 2001) which assumes 
process as reality and which accords primacy to actions/practices over self-contained individuals, organizations, or structures. From this process-based practice perspective, actions and learning are not always construed as the conscious "doings" of pre-existing individuals or organizations. Rather individuals and organizations are themselves regarded as temporarily constituted by "bundles” of socially-transmitted practices. Practices precede and give rise to individuation, not the other way around. Learnt social practices enable us to distinguish ourselves from others and hence to define our individual and collective identities. But such practices are not deterministic in that individual members of collectives while "carriers" of such practices are neither merely cultural dopes nor autonomous beings (Reckwitz 2002, 256). Instead, they draw from such established practices to express themselves individually (Reckwitz 2002, 251) when dealing with novel situation. Practice theory, therefore, seeks to find an explanatory middle-ground between the implied determinism of pre-existing structures and the unbridled autonomy of individual agency by focusing on actual actions and practices as the generative mechanism for understanding phenomena in the social world, including especially that of the learning organization. It replaces a cognitivist, meaning-based cultural perspective (Cook and Yanow 1993) with a non-cognitivist, practice-based understanding of how skills are learnt and transmitted mostly unconsciously within a community of practitioners. Such a practice-based view, however, is predicated upon an understanding of ultimate reality as perpetually fluxing and becoming.

\section{A process-philosophical perspective}

The idea that reality is perpetually changing and becoming has its roots in the ancient Greek philosopher Heraclitus in the West while in the East, it is patently evident in the I Ching 
(Book of Change) and in the writings of Lao Tzu and Chuang Tzu (in Chan 1963). Heraclitus, a native of Ephesus in ancient Greece emphasized the primacy of a fluxing, changeable, and emergent world whilst Parmenides his successor from Elea insisted upon the permanent and unchangeable nature of reality. Over the course of Western history, it has been the Parmenidean-inspired mind-set that has dominated much of Western thought, while Heraclitean thought remains a subsidiary tradition. In the East, however, the idea that change is always going on and that becoming, perishing and renewal are inexorable features of reality, has been widely but tacitly accepted for several millenia. While the neo-Parmenidean world-view elevates substance, stability, and simple location as quintessential aspects of reality (Whitehead 1926/1985, 58-63) so that order, form, and self-identity are ontologically privileged over disorder, flux, and change, a Heraclitean-based world-view accepts that "all things flow” in a continuous self-generating process of becoming and changing; things and entities, therefore, are viewed as relatively stabilized patterns of relational configurations forged through practice rather than solid, stable substances. For Heraclitus, "all things come to pass through compulsion of strife” (Heraclitus, quoted in P.E. Wheelwright, Heraclitus, 1974, 29); conflict, struggles, and temporary reconciliations are unavoidably the very stuff of life. All our human accomplishments are merely temporary overcomings rather than permanent achievements. Unlike the Parmenidean-inspired system of thought which assumes the primacy of atomistic individuals, and hence human agency, process-philosophical thought insists that individuals are merely temporarily-stabilized bundles of social practices. In more recent times, various important thinkers, especially Henri Bergson (1911/1998), William James (1911/1996), and Alfred North Whitehead (1926/1985; 1929), have reiterated the primacy of movement, change and becoming over that of Parmenidean substantial entities and this rediscovery can provide an alternative understanding of the nature and workings of the learning organization. 
To begin with, if process is reality, if it is simply a "big blooming, buzzing confusion" (James 1911/1996, 50), it is also eminently unliveable. Social life is not possible amidst equivocality and that is precisely why there is a need to "enact” a "surrogate” reality (Weick 1979, 177). The construction of social reality—communities, societies, institutions, organizations, and individuals - then, is our way of dealing with this inherent equivocality that we face existentially. But these are inevitably temporary accomplishments; creep, decay, and degeneration constantly threaten our established social order at every turn. There is a pervasive entropic tendency immanent in all social systems. So much so that constant learning and adaptation are required to stave off the immanent disruptive forces of change that constantly threatening our stabilities. Effective coping actions taken gradually aggregate and stabilize into social practices that therefrom serve as the "building blocks" of social life. They help us forge unique communities/societies/institutions/organizations and provide them with a distinctive and often idiosyncratic way of living and coping that reflect the environmental circumstances the social unit finds itself in. For example, our modes of dwelling have been radically transformed throughout human history through the creative reconfiguring and transformation of the natural resources we find immediately available around us. Thus, whilst primitive man sought shelter in caves and then, when forced to by shifting environmental circumstances to find food afar, to build temporary shelters made up of wood from the trees, skin from animals, and so on, modern man (sic) is able to build more permanent structures because of a learnt ability to creatively transform the natural resources available to create more permanent stable structures. In each situation, the hunter-gatherers, the nomadic tribes, the planters and builders, all found practical means for responding to their extenuating circumstances; they tacitly learned the necessary capabilities, skills and practices to creatively produce artefacts that helped transform and enhanced their ways of life. 
Thus, collectively-learnt material practices and "know how" enable modern societies to skilfully extract iron ore from the mountain sides, smelt them into ingots and transform them into steel girders to build permanent structures for their accommodation. Similarly, through trial and error practices we discover that sand, soda, ash, and limestone can be brought together to produce glass which we then use for windows to ensure more indoor light in our abodes. But while initially, glass could only be produced in small pieces so that they had to be bound together by lead strips to create small leaded glass windows, the advent of sheet glass was a major advancement in glass production. Sheet glass, however, had to be tediously ground and polished to enable them to be used and it was only in the early 1950s that it was discovered that the practice of floating molten glass onto a film of molten tin gives a perfectly flat glass sheet (Pilkington 1969) without any need for grinding or polishing and with that the whole glass world was transformed. Today, glass is a ubiquitous feature of our everyday life; we use it for our homes, to construct the glass-adorned skyscrapers, the all-glass Lourve Museum in Paris, and so on. It is almost unthinkable to be without glass. Yet, in all this development, it is the constant refinement of practices through experimental learning and local adaptive action that has resulted in the impressive advancements. The same is true for social practices.

Social and organizational life requires a "workable level of certainty” (Weick 1979, 6) and the removal of equivocality (albeit often temporary) is necessary for us to engage in productive exchanges and to build stable relationships. Consequently, there is an existential need to create arbitrary distinctions out of this “aboriginal sensible muchness” (James 1911/1996, 50) that is the reality of our lived experience. Thus, “in the sky 'constellations,' on the earth 'beach,' 'sea,' 'cliff,' 'bushes,' 'grass'. Out of time we cut 'days' and 'nights,' 'summers,' and 'winters.' We say what each part of the sensible continuum is, and all these abstract whats are concepts” (James 1911/1996, 50, emphasis in original). In this way, we are 
able to "harness perceptual reality . . . to drive it better to our ends” (James 1911/1996, 65, emphasis in original). However, there is a price to pay for reducing our sense experiences into conceptual categories. While absolute reality is relentlessly ever flowing, our socially constructed "surrogate” reality offers a semblance of stability, coherence and predictability necessary for the establishment of social relations. Such a reality, while practically useful and “ministerial,” nevertheless “falsify as well as omit” (James 1911/1996, 79). Our acts of cognition and representation create "simplified editions of immediate matters of fact" (Whitehead 1926/1985, 66). Consequently, we regularly succumb to what Whitehead calls the “Fallacy of Misplaced Concreteness” (Whitehead 1926/1985, 64); the tendency to mistake our representations (i.e., our surrogate reality) for lived reality. What this means is that operating at the level of cognitive learning leads us to an ever-widening gap between "theory” and “practice” because we increasingly base our learning and our actions on representations rather than reality itself. Consequently, we respond to our "surrogate” reality rather than the reality of lived experience so that oftentimes our cognitive learning proves to be inadequate in resolving our practical concerns. The way to circumvent this problem is to begin by acknowledging the primacy of actions and practices as the basis for constructing the reality that we find so necessary and familiar and to recognize the need to recur to our lived experience for learning and resolving practical concerns.

\section{Perceptual learning, actions and practices}

Within the field of ecological psychology, the works of J.J. Gibson and his wife Eleanor Gibson (Gibson and Gibson 1955; Gibson 1979) have been instrumental in championing the radical idea that perceptual learning involving direct extracting of information from the 
environment precedes cognitive forms of learning. For both J.J. Gibson and Eleanor Gibson, humans learn out of the necessity to survive by actively interacting with their environment. In their view, we are fundamentally not so much information processors, but information “hunter-gatherers;” the primary task of active perception is the careful extraction of "optic invariants” from the ongoing fluidity of environmental changes in order to enable us to act effectively and this process is very "radically different from a process of constructing an internal model of the world” (J.J. Gibson 1973, 396). The skill involved in active perception entails the capacity for observing closely and detecting what the environment affords us in terms of possibilities for action. Learning, as such, is not so much about manipulating abstract symbols and establishing meaning, but about the process of studiously "differentiating previously vague impression” and not conceptually “enriching previously meager sensations” (Gibson and Gibson 1955, 34) through symbols. Or as Bateson (1972, 453, emphasis in original) puts it so well, it is about detecting the subtle "difference which makes a difference" in the extant environment. Understood thus, learning is not fundamentally about gathering abstract “facts” existing “out there;” rather it is about perceptually detecting those material differences that makes a difference and understanding their practical significance and consequences; this is the elementary unit of information. Genuine know-how, therefore, is experienced as the capacity for "finer and finer discriminations of situations paired with the appropriate response to each” (Dreyfus 2002, 367). Hence learning, is not so much about constructing new descriptions of the world, but about discovering new information (i.e. making finer discriminations) from the environment (Gibson 1979). Effective learning entails the process in which perceptual information is increasingly differentiated and recognized as specific to the things in the world and to what one can do with those things. This focus on differentiation and increasing specificity sets the Gibsons' ecological theory apart from traditional theories of learning. In particular, what is learnt in perceptual learning are 
“affordances” in the environment that offer possibilities for action (Gibson 1979) and these possibilities depend on the fit between the animal's bodily capabilities and the physical properties of the environment.

Perception of an affordance, therefore, entails the registering of a value-rich ecological array that contains potential for the environmental participant in a varied but finite number of ways. Thus, water affords drinking but does not afford respiration. Its surface affords support to some small insects, but not to humans. Similarly, a knee-high, flat, and solid surface that affords sitting for an adult will not afford the same for a child; in this regard affordances are objective, but what they afford is relative and subjective to our capabilities (Gibson 1979). Furthermore, the richest and most elaborate affordances offered to humans are those social affordances provided us by other people who we interact with within the social realm. Affordances pervade the social realm of human interactions. Most importantly, the act of perceiving an affordance in the environment does not imply the need for cognitively representing it as a mental object before using it or acting on it. Rather the perceiving of an affordance entails a form of discriminative attunement whereby the social being learns the significance of aspects of the social environment that holds potential value for him/her. Yet this learning to discriminate precedes the creation of abstract mental images. The cognitive urge to fix, classify and represent material and social phenomena can prematurely reduce the rich range of possibilities afforded us by our extant environment. The paradox is that it rules out other possible ways of understanding and hence mobilising such objects, situations, and phenomena for alternative purposes.

Human societies, institutions and organizations therefore, thrive and prosper by relentlessly refining sensitivity to the variety of affordances proffered by their extant environment and learning to capitalize on them. Members of an inuit community, for instance, are clearly able to finely differentiate between different types of snow, understand their 
implications, and respond accordingly simply because of their constant exposure and prolonged immersion in snow conditions (Krupnik et al. 2010). For them, it is a matter of life and death. Thus, perception of affordances varies from culture to culture, from society to society and indeed from organization to organization. In this manner there is an irreducibly idiosyncratic complementarity between a participating community and the solicitations excited by its environment. This emphasis on the fundamental role of active perception and our immersed engagement with a specific environment helps us to develop an ecological understanding of the structure of human capabilities at its most rudimentary level. It paves the way for an ecologically-based understanding of how, in human societies, perceptual sensitivity and skilled practical coping is developed, refined, grown, and socially-transmitted through material social practices without ever relying on abstract meanings or representations and conscious deliberations. This insight, that primary learning happens through direct immersed engagement rather than through manipulating abstract symbols is what justifies the occasional observation that we should perhaps “act before we think” (March 1972, 423) so that we can discover what "could be" rather than what "is."

\section{Becoming a learning organization}

In a thoughtful piece, initially delivered on the occasion of his retirement and subsequently published in the Journal of Management Inquiry, James March (2003, 205) noted that within much of the social sciences, "portrayals of human action are overwhelmingly in a calculative and consequentialist tradition” whereby "[a]ction is seen as choice, and choice is seen as driven by anticipations, incentives, and desires.” All action, therefore, is viewed within the behavioural sciences as intentional, planned, and goal-directed. March has questioned this 
premise throughout his academic life. For him, the idea that goals, plans, and choices, all cognitive imperatives, have to be developed prior to taking action is "clearly false . . . Human choice behaviour is at least as much a process for discovering goals as for acting on them” (March 1972, 420, my emphasis). Therefore, individuals oftentimes in practice in the real world, “act before they think” (March 1972, 423). What March is getting at, is the deeply embedded assumption in social science that all action and learning must be preceded by prior cognition and deliberate intention. For him, this assumption is very questionable; people do act in a trail-and-error manner and make necessary adjustments as they go along most of the time. Yet, much of the literature on the learning organization continues to assume that learning is intentional, anticipatory, and cognition-based. Little attention is paid to the local, often spontaneous adaptive actions taken in situ and sponte sua, as the aggregative basis of organizational learning. The argument made here is that it is precisely these local adaptive actions which aggregate into established organizational practices and predispositions over time that provide the generic learning of the learning organization. Moreover, they are underpinned by a finely-honed perceptual sensitivity to environmental affordances and a corresponding habitus or modus operandi that distinguishes it from other organizations. These generic substrate capabilities, unconsciously learnt, rather than formalized knowledge learnt through the cognitive process, is what makes an organization adaptive and agile in the face of environmental uncertainty. Appreciating this requires an acceptance of the primacy of such non-cognitive practices and predispositions as the basis of organizational learning.

The implications of this alternative understanding of how capabilities are precognitively learnt and developed is the refocusing of attention on the refining of perceptual sensitivity and the corresponding trail-and-error nurturing of appropriate adaptive actions and responses to the exigencies of a dynamic organizational environment. Local perceptual sensitivities and in-situ adaptive actions that firm up as non-cognitive social practices provide 
the underlying capability substrate upon which subsequent cognitive activity can then takes place. Shared active perceptual learning of environmental solicitations and the affordances it proffers provides the true basis for the subsequent acquisition of skilled capabilities for capitalizing on the possibilities available. The true learning organization therefore is one that is fundamentally immersed and "in touch" and hence highly attuned to its internal and external environmental circumstances and this allows it to envision new vistas of possibility amidst the nuanced unfolding of the dynamic circumstances it finds itself in. The true learning organization is fundamentally a serial innovator that constantly sees novel possibilities and opportunities to innovate in the very depths of the environmental uncertainty it finds itself in. In the literature on evolutionary biology, Gould and Vrba (1982) have introduced the interesting concept of “exaptation” which they contrast against the more traditional Darwinian understanding of natural selection and passive adaptation. For Gould and Vrba, while adaptation presumes the need for attaining a passive "fit” with environmental imperatives, exaptation denotes the more active and exploratory process of how environmental affordances are often surprisingly co-opted for novel use so that "features that now enhance fitness ... were not built by natural selection for their current role” (Gould and Vrba 1982, 4). For example, Gould and Vrba show, contrary to the received wisdom that feathers evolved to enable flight, that the "initial development of feathers in an ancestor was for the function of insulation and not for flight” (Gould and Vrba 1982, 7); in actual fact feathers evolved from hair to deal with the need for thermal insulation but the then heavily feathered creatures accidentally discovered aerodynamic lift and hence the possibility of flight in the course of their running! This is one example of the significance of the concept of exaptation; that features of the organism/environment can be co-opted for ever-novel possibilities previously un-envisaged. This insight has been used by organizational scholars to use the term exaptation to show the "repurposing of artifacts, technologies, processes, skills, organizations, and 
resources for emergent uses that they were not (initially) designed for” (Dew and Sarasvathy 2016, 167). Similarly, Andriani et al. (2017, 335-336) list several discoveries in the medical sector such as botox and Viagra that have been exapted for a different purpose than their original intended use. Exaptation leads to the production of novel reconfiguration of resources and capabilities and hence new product offerings. But this capacity for exaptation is inextricably linked to a deep sensitivity to affordances that in turn leads to the ability to see ever-more possibilities available for innovative exploitation. This is what makes for a true learning organization.

\section{Conclusion}

Much literature on the learning organization literature takes the process of learning to be essentially about the cognitive acquisition of facts and the process of formulating knowledge configurations, rules, routines, and procedures, etc. This way of understanding organizational learning underestimates the primacy and importance of non-cognitive and non-deliberate learning within organizations that go on all the time often unceremoniously and unnoticed. We argue here that prior to conscious learning, organizational members unconsciously acquire a substrate of generic capabilities through immersion in material social practices that crucially circumscribes their capacity to learn. This non-cognitive form of learning comprises a collectively-transmitted set of refined perceptual sensitivity to environmental affordances and an associated set of practical coping capabilities for dealing with the exigencies of their operating environment. It is this tacit ability to be perceptually attuned to the unfolding contours of a dynamically evolving external environment and then to respond effectively to it in situ and sponte sua, that make for a truly effective learning organization. A learning 
organization is one empirically-attuned to the subtle changes occurring in the environment that create windows of opportunities for active exploitation. This happens oftentimes through the process of exaptation in which artifacts, technologies, processes, and resources available are co-opted to create novel offerings. Ultimately, the learning organization is a serial innovator.

\section{Reference list}

Andriani, P., A. Ali, and M. Mastrogiorgio. 2017. "Measuring Exaptation and Its Impact on Innovation, Search, and Problem Solving.” Organization Science 28 (2): pp. 320-338.

Bateson, G. 1972. Steps to an Ecology of Mind. Chicago: University of Chicago Press.

Bergson, H. 1911/1998. Creative Evolution. Mineola, N.Y.: Dover Publications.

Bourdieu, P. 1990. The Logic of Practice. Cambridge: Polity Press.

Chan, W-T. 1963. A Sourcebook in Chinese Philosophy. Princeton, NJ: Princeton University Press.

Cook, S.D.N., and D. Yanow. 1993. “Culture and Organizational Learning.” Journal of Management Inquiry 2 (4): pp. 373-390.

Coopey, J. 1995. “The learning Organization, Power, Politics and Ideology Introduction.” Management Learning 26 (2): pp. 193-213.

Dew, N., and S.D. Sarasvathy. 2016. “Exaptation and Niche Construction: Behavioral Insights for an Evolutionary Theory.” Industrial and Corporate Change 25 (1): pp. 167-179.

Dreyfus, H.L. 1988. “The Socratic and Platonic Basis of Cognitivism.” AI \& SOCIETY 2 (2): pp. 99-112. 
Dreyfus, H.L. 2002. “Intelligence Without Representation - Merleau-Ponty’s Critique of Mental Representation.” Phenomenology and the Cognitive Sciences 1 (4): pp. 367383.

Garratt, B. 1986/2000. The Learning Organization. London: Harper Collins

Gibson, J.J. 1973. “Direct Visual Perception: A Reply to Gyr.” Psychological Bulletin 79 (6): pp. 396-397.

Gibson, J.J. 1979. The Ecological Approach to Visual Perception. Classic ed. New York: Psychology Press.

Gibson, J.J., and E.J. Gibson. 1955. “Perceptual Learning: Differentiation or Enrichment?” Psychological Review 62 (1): pp. 32-41.

Gould, S.J., and E.S. Vrba. 1982. "Exaptation: A Missing Term in the Science of Form.” Paleobiology 8 (01): pp. 4-15.

Hale, R. 2014. “Fundamentals of Action Learning.” Training Journal (August): pp. 30-36. Retrieved February 24, 2019, from https://www.trainingjournal.com/articles/feature/fundamentals-action-learning.

James, W. 1911/1996. Some Problems of Philosophy: A Beginning of an Introduction to Philosophy. New York: Longman Green.

Kleiner, A., B. Smith, C. Roberts, P. Senge, and R. Ross. 1994. The Fifth Discipline Fieldbook: Strategies for Building a Learning Organization. New York: Nicholas Brealey Publishing

Krupnik, I., C. Aporta, S. Gearheard, G.J. Laidler, and L.K. Holm. 2010. SIKU: Knowing Our Ice. New York: Springer.

March, J.G. 1972. “Model Bias in Social Action.” Review of Educational Research 42 (4): pp. 413-429.

March, J.G. 2003. “A Scholar’s Quest.” Journal of Management Inquiry 12 (3): pp. 205-207. 
Marquardt, M.J. 2000. “Action Learning and Leadership.” The Learning Organization 7 (8): pp. 233-240.

Örtenblad, A. 2018. “What Does ‘Learning Organization’ Mean?” The Learning Organization 25 (3): pp. 150-158.

Pedler, M. (Ed.). 1991. Action Learning in Practice. 2nd ed. Aldershot, UK: Gower.

Pedler, M., T. Boydell, and J. Burgoyne. 1989. “Towards the Learning Company.” Management Learning 20 (1): pp. 1-8.

Pedler, M., and J. Burgoyne. 2017. “Is the Learning Organization Still Alive?” The Learning Organization 24 (2): pp. 119-126.

Pilkington, A.L.B. 1969. "Review Lecture: The Float Glass Process.” Proceedings of the Royal Society of London: Series A, Mathematical and Physical Sciences 314 (1516): pp. $1-25$.

Raelin, J.A. 1997. “Action Learning and Action Science: Are They Different?” Organizational Dynamics 26 (1): pp. 21-34.

Reckwitz, A. 2002. “Towards a Theory of Social Practices: A Development in Culturalist Theorizing.” European Journal of Social Theory 5 (2): pp. 243-263.

Revans, R. 1980. Action Learning: New Techniques for Management. London: Blond and Briggs.

Santa, M. 2015. “Learning Organization Review: A ‘Good’ Theory Perspective.” The Learning Organization 22 (5): pp. 242-270.

Schatzki, T.R. 2001. “Introduction: Practice Theory.” In The Practice Turn in Contemporary Theory, edited by T.R. Schatzki, K. Knorr-Cetina, and E. von Savigny, pp. 1-14. London: Routledge.

Senge, P. 1990.The Fifth Discipline: The Art and Practice of the Learning Organization. New York: Doubleday. 
Weick, K.E. 1979. The Social Psychology of Organizing. Reading, MA: Addison-Wesley.

Wheelwright, P. 1974. Heraclitus. New York: Atheneum.

Whitehead, A.N. 1926/1985. Science and the Modern World. London: Free Association Books.

Whitehead, A.N. 1929. Process and Reality: An Essay in Cosmology. New York: Free Press. 